\title{
Unexpected malignant pericardial mesothelioma presenting as pericardial constriction
}

\author{
Oc $\mathrm{M}^{1}$, Oc $\mathrm{B}^{2}$, Dogan $\mathrm{R}^{1}$ \\ 29 May Private Hospital, Department of Cardiovascular Surgery, Ankara, Turkey. mehmetoc@hotmail.com
}

\begin{abstract}
Pericardial mesothelioma is a rare and highly aggressive and lethal cardiac tumour. A 25-year-old male patient who was complaining of fever, night sweats, shortness of breath and palpitations after an upper respiratory system infection was admitted in May 2008. He had a history of 12 years exposure to asbestos. When the patient was referred to our hospital in June 2008, his complaints of palpitations and shortness of breath were continuing. He had oedema of legs and a venous swelling on his neck. The echocardiography showed pericardial effusion and pericardial thickening which were also found on the CT. Through median sternotomy a pericardectomy and tumor resection were performed. Histological and immunohistochemical findings lead to the diagnosis of malignant pericardial mesothelioma. In conclusion, there is still not a radical therapy for primary pericardial mesothelioma. Surgery is done to prevent cardiac tamponade and relieves constriction (Fig. 1, Ref. 12). Full Text in PDF www.elis.sk.

Key words: pericardial mesothelioma, pericardial constriction, primary malignant pericardial mesothelioma.
\end{abstract}

Pericardial mesothelioma is a rare and highly aggressive and lethal cardiac tumour. Pericardial mesotheliomas overall prognosis is poor. Clinical symptoms are constrictive pericarditis, hemopericardium cardiac tamponade, and cardiac failure. Pericardial mesothelioma is still a therapeutic and diagnostic controversy. Surgery is the main treatment. Chemotherapy is used to reduce the tumour mass but response to radiotherapy is poor (1).

\section{Case report}

A 25-year-old male patient who was complaining of fever, night sweats, shortness of breath and palpitations after an upper respiratory system infection was admitted in May 2008. He had a history of 12 years exposure to asbestos. While he was in hospital an increase in pericardial effusion meant that tamponade was discovered in the patient and pericardiosynthesis and a pericard biopsy were performed. $700 \mathrm{ml}$ of hemorrhagic pericardial effusion was aspirated. There was no malignancy in the pericardial sitology but the biopsy result showed infiltration by a low-differential malign tumor. However, in the primary etiology cardiac effusion was not observed.

When the patient was referred to our hospital in June 2008, his complaints of palpitations and shortness of breath were continuing. He had edema of legs and a venous swelling on his neck.

129 May Private Hospital, Department of Cardiovascular Surgery, Ankara, and 22 May Private Hospital, Department of Anesthesiology and Reanimation, Ankara, Turkey

Address for correspondence: M. Oc, MD, 29 May Private Hospital Department of Cardiovascular Surgery Cankaya, Ankara, Turkey 06610 Phone: +90.312 .5932929$

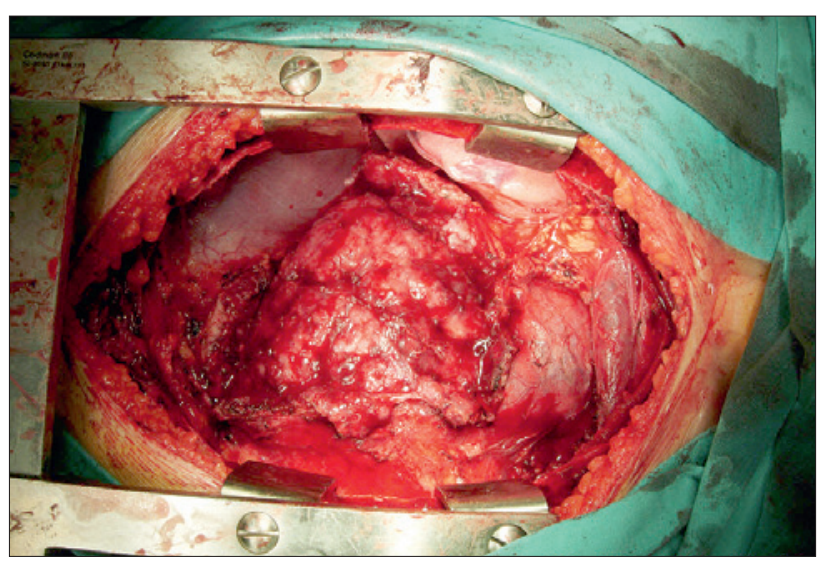

Fig. 1. Operative images of malignant pericardial mesothelioma.

The echocardiography showed pericardial effusion and pericardial thickening which were also found on CT. The patient's blood biochemistry found reactive inflammation (leukocyte count 11400, C-reactive protein $87.3 \mathrm{mg} / \mathrm{L}$ ) and liver dysfunction (lactate dehydrogenase $2020 \mathrm{IU} / \mathrm{L}$ ). Through median sternotomy pericardectomy and tumors resection were performed. The pericardium was $2-3 \mathrm{~cm}$ thick, white, homogeneous, and very strongly adherent to the myocardium. As much as possible, of the pericard and tumour tissues were removed, while protecting the phrenic nerve (Fig. 1). Microscopically, in the desmoplastic stroma, solid nodular islands, rosette-like structures, forming short fascicles and focal papillary processes were observed, in places, showing the monotonous central necrosis, cellular tumor tissue was observed. Tumor cells; eosinophilic cytoplasm, vesicular nuclei, polygonal, spindle-shaped in places and often show mitotic activity. Immunohistochemical- 
ly, pankeratin, CK17, LMW keratin, calretinin with tumor cells showed immune positivity. In the light of histological and immunohistochemical findings, the case was diagnosed as malignant pericardial mesothelioma. The patient was discharged a week after the operation with all his complaints having been treated. I

\section{Discussion}

Primary tumours of the pericardium are extremely rare. One of the largest necropsy series gives an incidence of $0.0022 \%$ in 500000 cases $(1,2)$. Secondary tumours are more common, metastasising mostly from the lung, breast, melanomas, lymphoma, or leukaemia (1). For primary tumours of the pericardium three histological types have been described: epithelial, spindle cell, and mixed (3). Prognosis is poor with survival after diagnosis ranging from six weeks to 15 months (1). The incidence of primary tumours of pericardium is in both sexes almost equal, within the age range of 1-79 years. The tumour is commonly diagnosed at an advanced stage and often results in evidence of constriction caused by tumour expansion or associated with serous or hemorrhagic pericardial effusion.

Pericardial mesothelioma signs and symptoms (such as chest pain, dyspnea, cough, pericardial rub, and pulses paradoxes) are nonspecific, and are related mostly to the compromise of cardiac function caused by tumour mass, effusion, or both. This nonspecificity may lead to diagnostic consideration or treatment of other disease states associated with pericardial effusion, such as rheumatic fever, metastatic disease, dissecting aortic aneurysm, viral syndrome, collagen vascular disease, and tuberculosis (4-9). The role of asbestos exposure as a causative factor in the development of pericardial mesothelioma is not certain, but this is seen only in cases with coexistent asbestos related pleural disease (10). Asbestos exposure has been documented in a few patients. However, in our case, there was exposure to asbestos.

Pericardial effusion in the course of mesothelioma may be difficult to aspirate. Thoracic X-ray, Echocardiography, Magnetic resonance imaging, CT and cardiac catheterization are commonly used initial investigative tools. Other investigations such as immunohistochemistry, cytological examination, and high pericardial hyaluronic acid content of the pericardial aspirate can be diagnostic (11) Primary pericardial mesothelioma in differential diagnosis in patients presenting with recurrent or unexplained pericardial effusion can be considered. Most cases of pericardial mesothelioma have been diagnosed by histology after surgery for misdiagnosed constrictive pericarditis or on autopsy, treatment following a late diagnosis is usually unsatisfactory (12). Similarly, our case was diagnosed late but, the postoperative period was uneventful.

\section{Conclusion}

There is still not a radical therapy for primary pericardial mesothelioma. Surgery is done to prevent cardiac tamponade and relieves constriction. Early diagnosis and surgery may prolong survival in some patients. In the future, inhibition of growth factors, photodynamic treatment, vaccines, and molecular chemotherapy may be used in the treatment.

\section{References}

1. Kralstein J, Frishman W. Malignant pericardial diseases: diagnosis and treatment. Am Heart J 1987; 113: 785-790.

2. Okura Y, Kato K, Hanawa H, et al Pericardial mesothelioma secreting thrombomodulin. Am Heart J 1996; 132: 1309-1311.

3. Yilling FP, Schlant RC, Hertzler GL, Krzyaniak R. Pericardial mesothelioma. Chest 1982; 81: 520-523.

4. Shin MS, Ho KJ, Liu LB. Pericardial mesothelioma masquerading as rheumatic heart disease. Arch Intern Med 1977; 137: 257.

5. Llewellyn M, Atkinson MW, Fabri B. Pericardial constriction caused by primary mesothelioma. Br Heart J 1987; 57: 54-57.

6. Wolverson MK, Grider RD, Sundaram M, Heiberg E, Johnson F. Demonstration of unsuspected malignant disease of the pericardium by computed tomography. J Comput Tomogr 1980; 4: 330-333.

7. Coplan NL, Kennish AJ, Burgess NL, Deligdish L, Goldman ME. Pericardial mesothelioma masquerading as a benign pericardial effusion. J Am Coll Cardiol 1984; 4: 1307-1310.

8. Nishikimi T. Ochi H, Hirota K, Ikuno Y, Oku H, Takeuchi K, Takeda T. Primary pericardial mesothelioma detected by gallium- 67 scintigraphy. J NuLcl Med 1987; 28: 1210-1212.

9. Rose DS, Vigneswvaran WT, Bovill BA. Riordan JF, Sapsford RN, Stanbridge RD. Primary pericardial mesothelioma presenting as tuberculous pericarditis. Postgrad Med J 1992; 68: 137-139.

10. Loire R, Tabib A. Malignant mesothelioma of the pericardium: an anatomoclinical study of 10 cases. Arch Mal Coeur Vaiss 1994; 87: 255-262.

11. Nambiar CA, Tareif HE, Kishore KU, Ravindran J, Banerjee AK. Primary pericardial mesothelioma: one year event free survival. Am Heart J 1992; 124: 802-803.

12. Watanabe A, Sakata J, Kawamura H, Yamada O, Matsuyama T. Primary pericardial mesothelioma presenting as constrictive pericarditis: a case report. Jpn Circ J 2000; 64 (5): 385-388. 